\title{
Celdas solares en Colombia: síntesis y optimización de películas delgadas de Molibdeno por sputtering para ser usadas en la fabricación de celdas solares tipo tándem
}

\author{
Josué Itsman Clavijo Penagos` \\ Departamento de Física, Universidad Nacional de Colombia, Bogotá D.C., Colombia
}

Fecha de Entrega: Enero 26 DE 2012

FECha de EVAluación: FeBrero 16 DE 2012

FECHA DE APROBACIÓN: MAYO 3 DE 2012

\begin{abstract}
Resumen En el presente trabajo se sintetizaron, caracterizaron y estudiaron una serie de capas delgadas de molibdeno metálico, optimizando sus propiedades para ser usadas como contactos eléctricos en celdas solares tipo tándem. Se estableció el dispositivo experimental adecuado para la preparación de las películas delgadas ya mencionadas, y a través de medidas de resistencia eléctrica, difracción de rayos $\mathrm{X}$, microscopía de fuerza atómica y perfilometría en 2D, se encontraron los parámetros de síntesis que aseguran para los materiales propiedades óptimas en términos de cristalinidad, espesor de película y resistencia de hoja $R_{S}$. Se logró optimizar las películas presentando la resistencia eléctrica, espesor y cristalinidad apropiadas para ser usadas como contacto eléctrico inferior en celdas solares tipo tándem.
\end{abstract}

Palabras Clave: celdas solares, dispositivos fotovoltaicos, películas delgadas, Molibdeno, XRD, AFM, semiconductores.

\begin{abstract}
This paper summarizes, characterizes, and studies a series of thin layers of metallic molybdenum in order to optimize their properties to be used as electric contacts in tandem solar cells. We established an experimental device that was suitable for preparing those thin layers; besides, through electric resistance measures, X-ray diffraction, atomic strength, and 2D profilometry, it was possible to find synthesis parameters to ensure material with ideal properties regarding clearness, film thickness, and $R_{S}$ leaf. The films were optimized because they showed the ideal electrical resistance, thickness, and clearness to be used as inferior electrical contacts in tandem solar cells.
\end{abstract}

Keywords: solar cells, photovoltaic devices, thin layers, molybdenum, $\mathrm{XRD}, \mathrm{AFM}$, semiconductors.

\footnotetext{
* Dr. Sc. en Ciencias (tesis con mención meritoria), Universidad Nacional de Colombia. Áreas de interés: celdas solares, fotocatálisis, física de semiconductores, fisicoquímica. jiclavijop@unal.edu.co
} 


\section{Introducción}

La generación fotovoltaica de electricidad se realiza a través de módulos solares fabricados usando dos tecnologías diferentes. La denominada tecnología de películas delgadas (también conocida como de segunda generación) ha sido muy exitosa mediante la fabricación de módulos basados en tres tipos diferentes de materiales: $\mathrm{Cu}(\mathrm{In}, \mathrm{Ga}) \mathrm{Se}_{2}$ (CIGS), CdTe y silicio con estructura amorfa (a-Si). El mercado mundial de módulos está dominado por la tecnología de primera generación de silicio cristalino y policristalino [1], sin embargo la tecnología de capa delgada está creciendo actualmente a mayor velocidad que la de silicio debido a su bajo costo en comparación con la tecnología de primera generación.

Una celda solar de segunda generación requiere de varias capas para su funcionamiento: contactos eléctricos, capa absorbente, ventana óptica y capas antirreflectoras. El óptimo desempeño de la celda depende, por supuesto, de la calidad de todas y cada una de las capas constituyentes. En el presente trabajo se optimizaron las propiedades adecuadas para que las capas de molibdeno (Mo) pudieran usarse como contactos eléctricos en la fabricación de celdas solares tipo tándem. En la parte estructural, se necesita que la capa de Mo presente un alto grado de empaquetamiento para promover el transporte eléctrico, el cual se evalúa a través de medidas de propiedades eléctricas como la resistencia de hoja $R_{S}$ (Sheet Resistance), además de poseer un alto grado de cristalinidad y un buen espesor manteniendo muy baja la resistencia de hoja, la cual debe ser debe ser del orden de $10^{-1} \Omega / \square$ (Ohm/square) [2], además de mantener una excelente adhesión y resistencia mecánica [3].

\section{Experimental}

El Mo se fabricó como películas delgadas sobre sustratos de vidrio SLG depositadas por el método de sputtering D.C de magnetrón (con configuración de electrodos tipo S-Gun), que es una técnica usada rutinariamente en laboratorio para la fabricación de capas delgadas de metales con mejores resultados que el sputtering RF [4]. El método de sputtering consiste en extraer átomos de un blanco (cátodo) por impacto iónico, los cuales son posteriormente condensados en un sustrato dando lugar a la formación de una película delgada del material del blanco. Los iones son generados a través de una descarga eléctrica luminiscente autosostenida o plasma, la cual se crea aplicando una diferencia de potencial del orden de $400 \mathrm{~V}$ entre dos electrodos que se encuentran en una cámara que contiene un gas inerte (generalmente Argón) a baja presión. De esta forma, los iones $\mathrm{Ar}^{+}$generados en el plasma y acelerados por el campo eléctrico generado entre los electrodos impactan el ánodo de Mo, el cual libera átomos en fase vapor que se acumulan en el sustrato ubicado en la parte superior de la cámara de sputtering, generando la película delgada de Mo. Un diagrama de bloques del sistema de sputtering usado se muestra en la figura 1, y el cuadro 1 muestra los parámetros experimentales usados en la fabricación de las películas delgadas de molibdeno. 


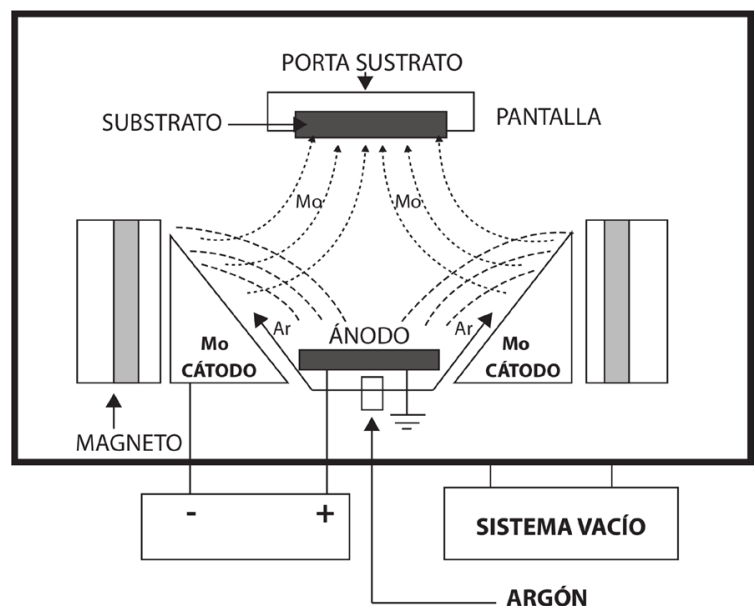

Figura 1. Diagrama de bloques del sistema de sputtering con configuración de electrodos tipo S-Gun, usado para la fabricación de películas delgadas de Mo.

\begin{tabular}{cc}
\hline Parámetros de fabricación de Mo & Magnitud \\
\hline Potencia de la descarga (W) & 200 \\
\hline Presión de Argón (mbar) & $2 \times 10^{-2}$ \\
\hline Voltaje del cátodo (V) & 400 \\
\hline Corriente del cátodo (A) & 0.5 \\
\hline Tiempo de fabricación (min) & 9 \\
\hline
\end{tabular}

Cuadro 1. Parámetros típicos de fabricación de películas delgadas de Mo.

\section{Resultados}

La fabricación del contacto inferior de Mo fue optimizada teniendo siempre como propiedad objetivo el valor de la resistencia de hoja $R_{S}$. En el presente trabajo dicho parámetro se optimizó mediante un análisis del efecto de los principales parámetros de fabricación (Presión parcial de Ar, potencia de la descarga luminiscente y corriente de iones) y del espesor sobre la resistencia de hoja. Inicialmente se varió el espesor de película de Mo variando el tiempo de sputtering $t_{S_{p}}$, manteniendo la corriente de iones $I_{S_{p}}$ y la presión parcial de Ar constantes. Posteriormente se prepararon películas manteniendo fijo el espesor y la presión parcial de Ar y variando potencia de la descarga eléctrica. La figura 2 muestra la variación de la resistencia de hoja $R_{S}$ y del espesor en función de $t_{S_{p}}$. Se observa que $R_{S}$ disminuye al aumentar el espesor (determinado para todas las 
películas por perfilometría en 2D) y que para espesores mayores que $1000 \mathrm{~nm}$, el valor de $R_{S}$ es menor que $10^{-1} \Omega / \square$ que es el valor adecuado para la aplicación como contacto eléctrico [2]. La disminución de $R_{S}$ con el aumento del espesor de las películas de Mo podría ser atribuido a un aumento de la movilidad de los portadores como consecuencia del aumento de tamaño de grano (ver figura 4) al incrementar el espesor de la capa de Mo.

La figura 3 presenta resultados de la variación de $R_{S}$ de películas de Mo en función de la potencia de la descarga eléctrica $P_{S_{p}}$ manteniendo el espesor de las películas en un valor alrededor de $1300 \mathrm{~nm}$. Se observa que $R_{S}$ disminuye al aumentar la potencia probablemente como consecuencia de un aumento de la movilidad de los portadores inducida por una reducción del ancho de la zona de frontera de grano (ver figura 5). Los resultados de la figura 3 revelan adicionalmente que en el rango de potencias estudiadas todas las muestras presentan valores de $R_{S}$ menores que $10^{-1} \Omega / \square$, indicando que independientemente de la potencia usada las muestras de Mo son adecuadas para ser usadas como contacto inferior de las celdas. Sin embargo se escogió fabricar las películas a $0,2 \mathrm{~kW}$ de potencia ya que es preferible trabajar a la menor potencia posible para que evitar un sobrecalentamiento del target.

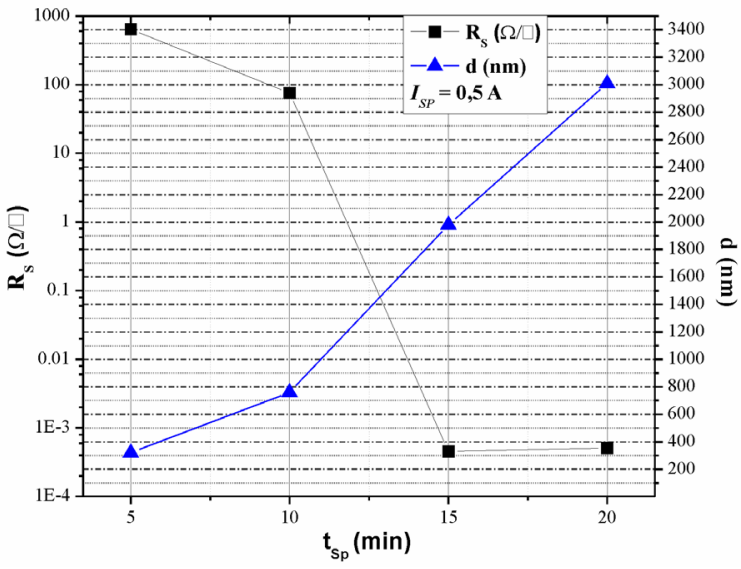

Figura 2. Variación del espesor de película y del consecuente valor de $R_{S}$ en función del tiempo de sputtering $t_{S_{p}}$ para películas delgadas de Mo. Para cada tiempo, los valores de espesor de película (azul) y de resistencia de hoja (negro) corresponden a una misma muestra. Las líneas se han adicionado sólo como guía visual.

La figura 4 muestra imágenes AFM típicas de películas de Mo con espesores entre 320 y $3010 \mathrm{~nm}$. Estos resultados muestran que el espesor afecta significativamente la morfología de las películas de Mo. En particular, para muestras de espesor menor que $1 \mu \mathrm{m}$ el tamaño de grano de las capas de Mo cambia con el 


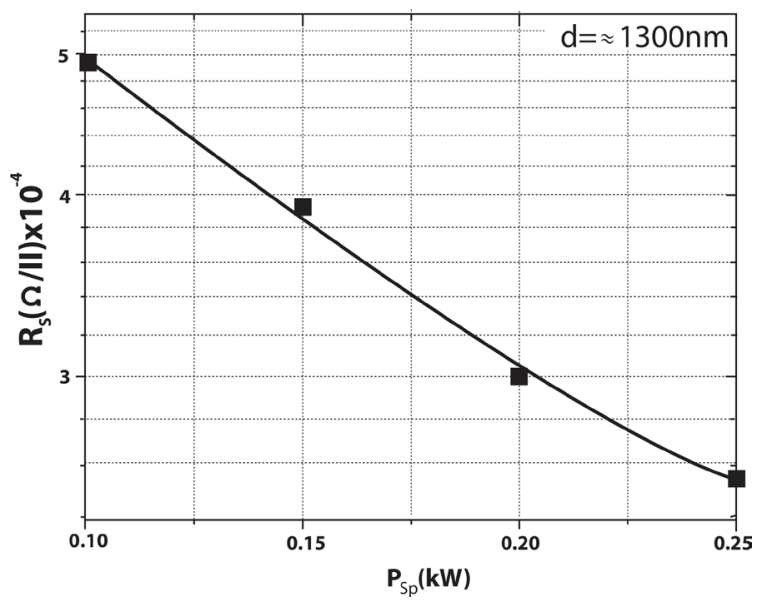

Figura 3. Variación de $R_{S}$ en función de la potencia de sputtering $P_{S_{p}}$ para películas delgadas de Mo. La línea se ha adicionado sólo como guía visual.

aumento del espesor de $110 \pm 5 \mathrm{~nm}$ para granos de forma circular a $420 \pm 6 \mathrm{~nm} \times$ $110 \pm 5 \mathrm{~nm}$ para granos con forma alargada; sin embargo para espesores mayores de $1 \mu \mathrm{m}$, el incremento del tamaño de grano es muy pequeño, manteniéndose la forma alargada de los mismos. Este comportamiento permite en parte explicar la disminución de $R_{S}$ con el aumento del espesor, ya que la movilidad de los portadores tiende a aumentar cundo el tamaño de grano aumenta debido a que en este caso los portadores tienen que atravesar un menor número de barreras de potencial en fronteras de grano.

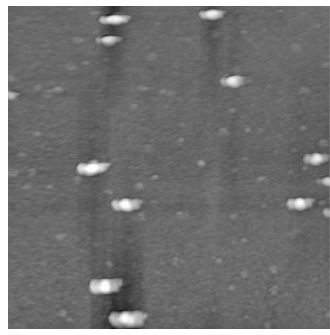

a)

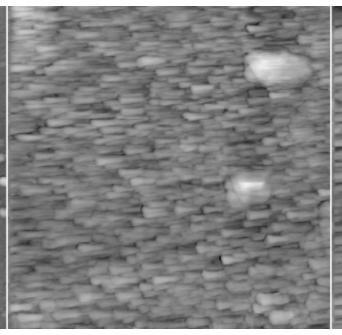

b)

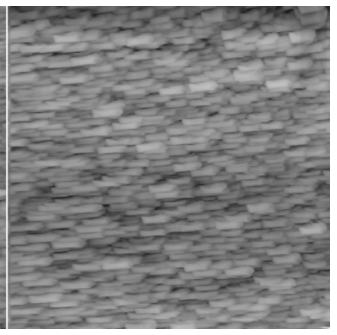

c)

Figura 4. Imágenes AFM típicas de películas delgadas de Mo con espesores diferentes: a) $d=320 \mathrm{~nm}, \mathbf{b}) d=3010 \mathrm{~nm} \mathrm{y} \mathrm{c)} d=1250 \mathrm{~nm}$. 
La figura 5 muestra imágenes AFM de películas de Mo de espesor similar, depositadas variando la potencia de la descarga eléctrica entre 150 y $250 \mathrm{~W}$. Se observa que en este caso el tamaño de grano no es significativamente afectado por la potencia; sin embargo el ancho de la región intergrano disminuye con el aumento de la potencia. Este comportamiento permite explicar la disminución de $R_{S}$ con el aumento de la potencia mostrado en la figura 3 , ya que la movilidad de los portadores tiende a aumentar cuando la región intergrano en la vecindad de las fronteras de grano disminuye debido a que se disminuyen las barreras de potencial existentes en las fronteras de grano $[5,6]$.

Las medidas de difracción de rayos X revelaron que películas de Mo con espesores menores que $1000 \mathrm{~nm}$ no presentan patrón de difracción, indicando que tienen una estructura amorfa; por el contrario, muestras con espesores superiores a $1000 \mathrm{~nm}$ presentan patrón de difracción indicando que este tipo de muestras crecen con estructura policristalina.

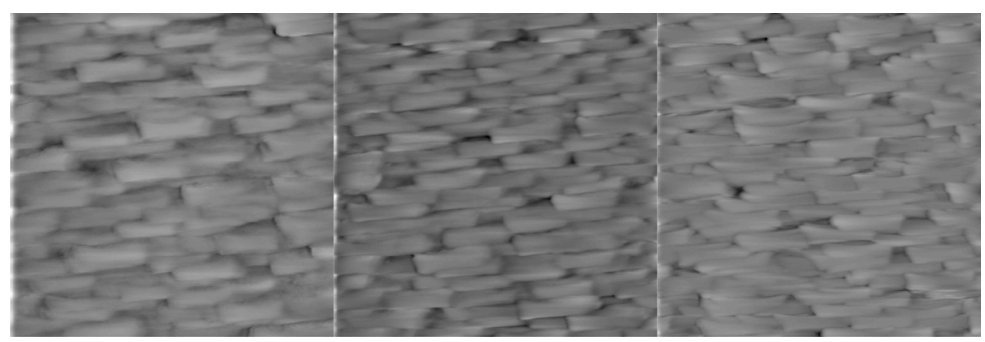

a)

b)

c)

Figura 5. Imágenes AFM de películas delgadas de Mo preparadas a diferentes potencias de descarga eléctrica: a) $150 \mathrm{~W}$, b) $d=200 \mathrm{~W}$ y c) $250 \mathrm{~W}$. Espesor de película $\approx 1300$ nm.

La figura 6 compara un difractograma experimental típico de una película de Mo de $1250 \mathrm{~nm}$ de espesor con el difractograma simulado mediante refinación por el método Rietveld [7]. La información reportada en la base de datos PDF (tarjeta \#00-042-1120) y la simulación teórica indican que las películas de molibdeno crecen con una estructura cúbica, con parámetro de red de $3,125 \AA$ y orientación preferencial [110]; dicha estructura es la deseada para este tipo de películas delgadas [8].

\section{Conclusiones}

Se lograron fabricar películas delgadas de Mo con propiedades óptimas para ser usadas en celdas solares tipo tándem. El espesor ideal obtenido es de $1300 \mathrm{~nm}$, con lo cual se asegura la estabilidad mecánica de la película que espesores menores no garantizan. La resistencia de hoja $R_{S}$, parámetro clave para el transporte de 


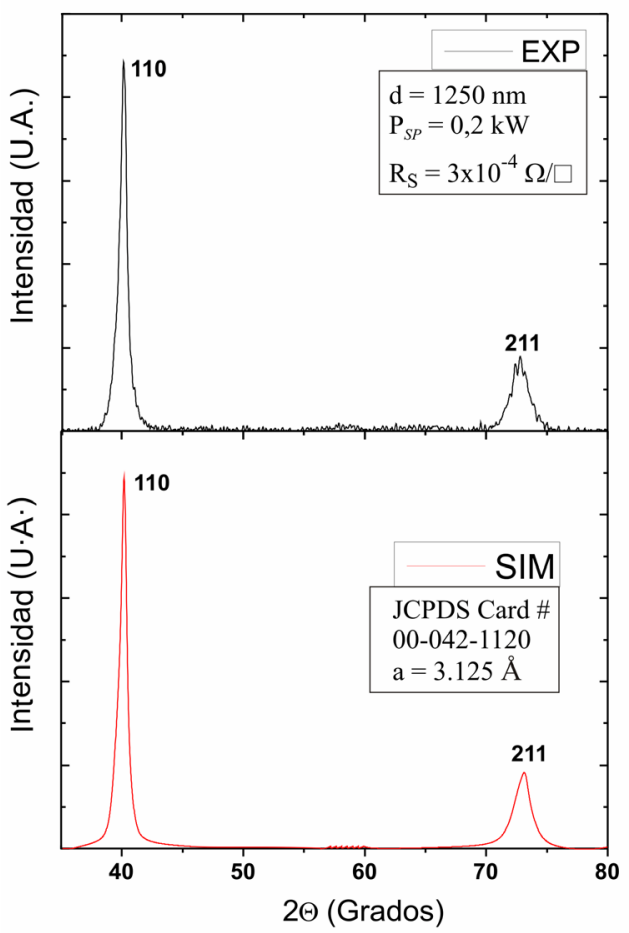

Figura 6. Comparación del difractograma de una película delgada de molibdeno fabricada con parámetros óptimos con el difractograma construido mediante simulación teórica usando el programa PowderCell.

electrones desde la celda hacia el circuito externo, es del orden de $10^{-4} \Omega / \square$, valor mucho menor que el límite máximo sugerido por NREL [2]. La cristalinidad y morfología de las muestras evidencia que la estructura es la de una capa de Mo policristalina cúbica, de alto grado de empaquetamiento y fronteras de grano reducidas que fomentan el transporte eléctrico a través de la película. Las películas de Mo así fabricadas fueron usadas con éxito en la fabricación de celdas solares, junto con las demás capas constitutivas también optimizadas dentro del proyecto investigativo del cual este trabajo hizo parte.

Agradecimientos: El autor desea agradecer al Departamento de Física de la Universidad Nacional de Colombia Sede Bogotá, a la DIB y al Grupo de Materiales Semiconductores y Energía Solar (GMS\&ES) y su director, el Dr. rer. nat. Gerardo Gordillo, por su invaluable ayuda para la realización de la tesis doctoral meritoria en la cual estuvo enmarcado el presente trabajo. 


\section{Referencias}

1. Parida, B., et al.: A review of solar photovoltaic technologies. Renewable and sustainable energy reviews 15 1625-1636. (2011)

2. Repins, I., et al.: Required Materials Properties for High-Efficiency CIGS Modules. National Renewable Energy Laboratory (NREL), Conference Paper NREL/CP520-46235, U.S. Department of Energy, Oak Ridge (TN), Julio de 2009, pp. 2. (2009)

3. Li, Z.H., et al.: Molybdenum thin film deposited by in-line DC magnetron sputtering as a back contact for CIGS solar cells. Applied surface science 257 9682-9688. (2011)

4. Jubault, M., et al.: Optimization of molybdenum thin films for electrodeposited CIGS solar cells. Solar energy materials \& Solar cells 95 S26-S31. (2011)

5. Yoon, Y.H., et al.: Optical analysis of the microstructure of a Mo back contact for $\mathrm{Cu}(\mathrm{In}, \mathrm{Ga}) \mathrm{Se}_{2}$ solar cells and its effects on Mo film properties and Na diffusivity. Solar energy materials \& Solar cells 95 2959-2964. (2011)

6. Gautron, E., et al.: Investigation of intergrain compounds in sputtered Mo films applied in CIGS-based solar cell. Surface \& Coatings technology, DOI: 10.1016/j.surfcoat.2011.09.030 (2011)

7. Rietveld, H.: A profile refinement method for nuclear and magnetic structure. Journal of Applied Crystallography 2 (2) 65-71. (1969)

8. Kashyout H.B. - A.E., et al.: Preparation and characterization of DC sputtered molybdenum thin films. Alexandria Engineering Journal 50 57-63. (2011) 